\title{
The Correlation of Tonal Shifts and Dialect Use with Socioeconomic Class in Dalian, China
}

\author{
Linda Pang ${ }^{1}$ \\ Correspondence: Linda Pang, Liansheng Street 103, Shahekou District, Dalian city, Liaoning Province, China. \\ Tel: 86-156-4085-9565. E-mail: 21.linda.pang@ gmail.com
}

Received: September 21, 2020

Accepted: October 23, 2020

Online Published: October 31, 2020

doi:10.5539/ass.v16n11p90

URL: https://doi.org/10.5539/ass.v16n11p90

\begin{abstract}
Drawing on Professor William Labov's seminal 1962 experiment, this paper examines tonal variation amongst employees of department stores targeting three different socioeconomic classes in Dalian, China. The experiment recorded pronunciations of the tone of $\mathrm{y} \overline{\mathrm{i}}$ (the word "first" in the phrase "first floor" 一楼), which is pronounced in first tone in standard Mandarin and shifted to the third tone in Dalian dialect. In this experiment, it was hypothesized that for the four department stores studied, an employee's tone in pronunciation of first tone words would shift towards the third tone the most in the store catering to lower socioeconomic classes and shift the least in the store catering to higher socioeconomic classes. From analyzing the data collected, the non-first tone pronunciations were the most frequent in the lowest ranking store and less frequent in the higher ranking store. Therefore, the salespersons' tonal shift in pronunciation is shown to correlate with the socioeconomic class of the customers being targeted.
\end{abstract}

Keywords: Dialect, socioeconomic class, tonal shifts

\section{Introduction}

\subsection{Background}

For the last 60 years, variationist sociolinguistics has highlighted the importance of social factors, other than geography, in determining language usage. Both individuals and entire speech communities adjust speech patterns on the basis of age, gender, political setting, and socioeconomics. For specific dialects, researchers have studied identifying factors causing dialectical differences that are not solely based on regional divisions. One such factor that has been studied is socioeconomic class differences. Professor William Labov, considered by many as a founding figure in the field of variationist sociolinguistics, conducted his original 1962 experiment "The social stratification of (r) in NYC department stores" as part of his larger study focusing on the social stratification of English in New York City (Labov, 2006). For this 2020 paper, Labov's 1962 experiment is replicated in Dalian, China for the similar purpose of examining the effect of socioeconomic class differences on language usage. In his experiment, Labov collected four tokens of syllable coda /r/ from 264 subjects in three department stores that targeted varying social classes: Saks Fifth Avenue (upper middle class), Macy's (lower middle class), and S. Klein's (working class). Labov utilized the rapid anonymous survey method with the salespersons in these stores by asking questions designed to contain "fourth floor" in the answer (Labov, 2006, p.56). The two postvocalic /r/ pronunciations were pronounced first and then the salespersons were asked to repeat their answer in order to collect the emphatic version of the same /r/ pronunciations. Through his study, Labov validated his initial hypothesis; salespersons in the highest ranked store had the highest values of (r), those in the middle ranked store had intermediate values of $(\mathrm{r})$, and those in the lowest ranked store had the lowest values of (r) (Labov, 2006, p. 42).

\subsection{Purpose}

In addition to Labov's experiment, other studies have been carried out with a similar focus on the relationship between class and language changes. One of these experiments was William Bright's study of dialectical differences within the Indian caste system. In his article "Social Dialect and Language History," Bright illustrates how the upper class has served as the initiator of linguistic changes in order to maintain a "prestige-marking difference" and how the lower class tries to "narrow the gap by imitating" (Bright, 1960, p. 424). The Brahmin language, or upper-class language, borrowed vocabulary from Sanskrit and English, creating vocabulary with new meanings, while the non-Brahmin, or mid to lower class language, used native vocabulary (Bright, 1960, 
p.424). This theory was further supported in the Detroit Dialect Study by Roger W. Shuy in terms of conscious and unconscious language changes based on social class differences. Specifically, Shuy tested the pronunciation of "-ing" in "participat-ing," and it was shown that the percent pronunciation of the word end "-ing" increased as the social level quartile increased. This showed the upper class using more conscious linguistic variations to distinguish itself as more elite than the other speakers (Shuy et al., 1967). While there have been previous experiments investigating the social stratification of English in various locations, there haven't been many studies with a similar focus on the social implications of language variations in the Chinese language, which is the primary purpose of this study.

\subsection{Chinese Language}

The Chinese language belongs to the Sino-Tibetan language family. Modern Standard Mandarin is currently the official language spoken across China, though there are many different regional dialects (Fangyan, also called topolects, referring to the Greek-derived neologism for "speech of a place") spoken within the nation (Weng, 2018, p.614). The language of interest in this experiment is the Dalian dialect, which has developed under the influence of traditional accents in Northeastern China and the accent from the eastern Shandong Province ("China Salvages," 2012). Dalian dialect is spoken mostly on the Liaodong Peninsula, including the city of Dalian and parts of Dandong and Yingkou (World Heritage Encyclopedia, n.d.). The dialect differs from Standard Mandarin in its frequent use of third and fourth tones to replace first and second tone pronunciations. This tonal shift in the dialect creates a harsh and forceful impression of the speaker, which is a defining characteristic of locals in the Northeastern regions. For instance, the phrase "to clean up" (收拾) is pronounced "Shòushi" in the Dalian dialect whereas the Standard Mandarin pronounciation of the phrase is "Shōushí". In this example, the first tone (Shōu) placed on the first syllable "shou" by Standard Mandarin is replaced by fourth tone (Shòu) in Dalian dialect and the second tone (shí) placed on the second syllable "shi" by Standard Mandarin is replaced by fourth tone (shì) in Dalian dialect.

Mandarin has been established as the standard Chinese language since 1909, but the widespread usage of Standard Mandarin did not start until 1949 when a massive effort to standardize language and improve overall literacy within China began (Wong, 2019). By the 1980s, about $60 \%$ of the population was fluent in Mandarin, and the government planned to reach $80 \%$ fluency by 2020 (Wong, 2019). The intended purpose of this standardization was to make communication across the nation possible with a common language, in place of distinctive regional dialects that were unintelligible to each other (Weng, 2018, p. 614) (the regional dialects differ from each other to about the same extent as the modern Romance languages (Egerod, 2013)). However, there are also cultural reasons for this language standardization due to the historical impression of higher education level and socioeconomic status associated with the ability to speak the national standard language. In China's 3,000 years of history, the standard language has long been associated with a higher class. Scholars such as Confucius preferred to use what was known as Yayan (雅言 "elegant speech") over the regional dialects of their hometowns, for Yayan was a language that only existed amongst the elite to communicate government matters and trading details (Wong, 2019). More recently, Gilliland's 2006 study on Shanghai Normal University students in China demonstrated the same perception of Standard Mandarin as superior to other dialects. In this study, Putonghua speakers were rated higher on social status (educated, intelligent) than Shanghainese dialect speakers. This overview of Chinese dialects provides the necessary background for further investigating the correlation between language use and social class in China.

\subsection{Hypothesis}

This 2020 experiment studies the correlation between dialect usage and socioeconomic classes in the city of Dalian, China, where four department stores were chosen to represent each class. The hypothesis was put forth stating that for the four department stores studied, an employee's tone in pronunciation of first tone words would shift towards the third tone the most in the store catering to lower socioeconomic classes and shift the least in the store catering to higher socioeconomic classes. In order to study this, the pronunciations of the same phrase by employees of the different department stores were compared. Based on their usage of Standard Mandarin or local dialect, the percentage of each language use would be used to assess the impact of social class on pronunciations and speaking preferences.

\section{Method}

\subsection{Procedure Model}

This 2020 study of Dalian department stores closely followed Labov's original methodology from his 1962 study of New York City department stores. In this study, data were collected using the same method of rapid anonymous survey, with the only difference being Chinese as the language of interest, instead of English (Labov, 
2006, p. 56). According to Mather, the procedure that Labov carried out neutralizes the "observer's paradox" (2012) which is a problem faced by many sociolinguists when the presence of the investigator influences the interviewed subjects' language usages and forms (Matthews, 2014). Since interviewees are not aware of the interviews being carried out in Labov's procedure, this survey method will likely elicit the most authentic response from the informants.

For the classification of each targeted social class and the related terminology, the 10-point MFY scale (from the Mobilization for Youth project) was followed. In Labov's book Social Stratification of English in New York City, the linear social scale was termed socioeconomic class. Labov quantified socioeconomic class on the MFY scale, combining the three objective characteristics of occupation, education, and family income into a single linear scale (Guy, 1988, p.42). In the original analysis, Labov grouped several points on this index to categorize those groups into lower class (0-1 on the scale), working class (2-5), lower middle class (6-8), and upper middle class (9). The latter three categories were used in this 2020 Dalian experiment to classify the four department stores into three rankings.

\subsection{Sampling Location Characteristics}

The four department stores selected in the order of targeting the lowest to the highest social classes were: Shuangxing Market (双兴市场), New Mart (新玛特), Parkland Mall (百年城), and Times Square (时代广场). According to the MFY scale that Labov used, Shuangxing Market targets the working class, New Mart targets the lower middle class, and both Parkland Mall and Times Square target the upper middle class (Guy, 1988, p.42). There were a number of factors considered when selecting these stores including: location, advertising, brands contained, price range, physical layout, and employees' outfits. Two higher-class stores were surveyed to obtain a representative sample since Times Square only has two floors (and very few employees as a result) and Parkland has few employees on each floor (due to the larger area of each section of the store and the closing of some stores due to the financial crisis caused by the 2020 coronavirus pandemic).

Characteristics of the highest-ranking stores:

- Times Square:

- located in the downtown business district near Renmin Road (where luxury goods stores are concentrated) and next to the Shangri-La Hotel and Furama Hotel (two of the most luxurious hotels in Dalian).

- offers about 30 international luxury brands and contains three high-end restaurants.

- to demonstrate its status as the home of internationally renowned brands (Dior, Louis Vuitton, Chanel, Giorgio Armani, Hermes, Gucci), Times Square invited Jiaxin Li (a famous Hong Kong actress), who has the same international image, to advertise for the mall (大连时代广场, n.d.).

- Parkland Mall

- located in the most prosperous commercial district of Qingniwaqiao.

- first to introduce the concept of shopping mall to Dalian.

- hosts multiple luxury brands including Burberry, Dior, and Giorgio Armani.

Characteristics of the middle-ranking store (New Mart):

- located in the same commercial district of Qingniwaqiao as Parkland Mall.

- the store advertises its ideology as fashion and beauty with affordable prices (大商新玛特购物休闲广 场, n.d.).

- contains new fashion brands like Only, Vero Moda, and Puma.

Characteristics of the lowest-ranking store (Shuangxin Market):

- located in Ganjingzi district (this district has the lowest real estate price out of all inner-city districts in Dalian).

- all-inclusive wholesale market.

- was built by renovating an abandoned medicine factory.

In addition to the store specific information listed above, the price range of particular items is indicative of the socioeconomic class of customers each store is targeting. From the four department stores where data were collected, the price ranges of women's clothing (specifically, women's jackets) were recorded, and their prices in 
dollar equivalents $(1$ dollar $\approx 7$ yuan) are given in Table 1.

Table 1. Price range of women's clothing (jackets) by store

\begin{tabular}{ccc}
\hline Store & Price Range of Women's Jacket (¥) & Equivalent \$ \\
\hline Shuangxing Market & $30-200$ & $4.29-28.57$ \\
New Mart & $100-2,000$ & $14.29-285.71$ \\
Parkland Mall & $1,000-10,000$ & $142.86-1,428.57$ \\
Times Square & $3,000-20,000$ & $428.57-2,857.14$ \\
\hline
\end{tabular}

The other two classification factors considered in the categorization of the department stores were: physical layout and employees' outfits. In Table 2, the features of each store that distinguish their customer class are summarized, and detailed explanations of each feature are included in the paragraphs below the chart.

Table 2. Store features that demonstrate the social class of target customer base

\begin{tabular}{ccccc}
\hline & Times Square & Parkland Mall & New Mart & Shuangxing Market \\
\hline $\begin{array}{c}\text { Physical } \\
\text { Layout }\end{array}$ & Spacious receptionist & receptionist & no individual shops & $\begin{array}{c}\text { each store has barely } \\
\text { enough space for all its } \\
\text { products }\end{array}$ \\
$\begin{array}{c}\text { Employee } \\
\text { Outfit }\end{array}$ & uniform: suits and skirts & $\begin{array}{c}\text { brand clothing: } \\
\text { T-shirts and pants }\end{array}$ & $\begin{array}{c}\text { overall store } \\
\text { uniform }\end{array}$ & $\begin{array}{c}\text { no uniform, cheaper } \\
\text { clothing }\end{array}$ \\
\hline
\end{tabular}

The physical layout of the stores can also serve as an indicator of the class differences of their targeted customer base. Times Square has two floors of approximately 17,000 square meters in area total. The building was designed by Arquitectonica (ARQ), an internationally renowned architectural design company that designed the "Westin Hotel" in Times Square, New York. All individual shops within the mall are spacious, and there is a large lobby area on the first floor with resting stations at the center. Parkland Mall has six floors and is approximately 80,000 square meters in area. The building is said to have the largest glass wall surface in Asia and also has resting stations in the lobby of the building. There is a receptionist in the lobby for both Times Square and Parkland Mall. For New Mart, the store has five floors and a cashier on each floor. There are no individual shops; rather, each brand occupies some space, and no physical wall divides the shops. In Shuangxing Market, there are six floors, and each shop is minimally spaced. It is difficult in some of the smaller shops to even stand up straight due to products hanging from above.

Another factor that distinguishes these stores is the employees' outfits. For Times Square, each brand has specially designed uniforms for their employees which are generally formal wear like suits for men and shirts and skirts for women. At New Mart, clothing brands' employees wear their brands' clothing which are mostly casual wear like T-shirts and pants, while other brands' employees have a uniform that is the same throughout New Mart. Lastly, for Shuangxin Market, there is no uniform or brand representative clothing because all the shops are individually owned. These vendors wear casual clothing that is visibly cheaper than those worn by Parkland Mall and New Mart employees.

\subsection{Sampling Procedure}

In July 2020, 99 pronunciation data from employees at four different department stores in Dalian, China were collected through rapid anonymous surveys. The researcher, who was also the interviewer, conducted these interviews while playing the role of a customer of each store and elicited pronunciations by asking for the location of a specific product or brand within the store. Similar to Labov's approach, the interviewer was dressed as a middle-class customer for all interviews and spoke standard Mandarin. In this experiment, the investigation consisted of only female subjects in order to eliminate gender-related confounding factors. The linguistic feature observed was the tonal shift in pronouncing the first word in the phrase "first floor". Standard Mandarin pronunciation of the word "first" has a flat high tone (first tone), while the Dalian dialect uses a contour tone (third tone). During the interviews, the question being asked was designed to get the answer of "first floor" (yi lóu), and the interviewer took down written notes after each encounter out of the sight of the informant (note table content included estimated age, floor within the store, and the perceived tone of pronunciation of yi [Tone 1, T2, T3, or T4]). For instance, the interviewer would ask, "Excuse me, on which floor are women's shoes?" knowing that they were located on the first floor. Then, the salesperson would most likely reply, "They are on the first floor (zài yī lóu)." These trials were carried out with as many subjects as possible on each floor of all four stores without being recognized as conducting a social experiment. 
Following this method, 11 interviews were obtained in Times Square, 22 in Parkland Mall, 33 in New Mart, and 36 in Shuangxing Market. Total interviewing time for the 99 informants was about 9 hours.

\subsection{Drawbacks in Procedure}

Although the data collection method has the advantage of neutralizing the "observer's paradox," there are several drawbacks in this rapid anonymous survey method. One disadvantage is that the interviewer could not ask informants questions about their age. As a result, attributing age to the informant was based only on the interviewer's impression which could be biased and inaccurate (Mather, 2012). Also, in terms of linguistic variations, the tonal shift in the pronunciations can sometimes be difficult to detect, and the classification of tone $1,2,3$, or 4 might be simplifying possible in-between tonal pronunciations. For instance, some pronunciations were heard by the interviewer to be slightly raised or suppressed (producing a sound that did not fit exactly within one tone) and might be miscategorized due to store biases or lack of evidence besides the subjective hearing experience. Lastly, there might have been a slight dialectical accent in the interviewer's speech that went undetected even by the interviewer herself despite the questions being expressed in the most standard language possible. A dialectical accent might be a source of influence for the response by the interviewed subjects (the salespersons).

The following sections present the results of this survey and analysis of possible reasons behind the correlations it revealed.

\section{Results}

\subsection{Overall Tonal Shift by Store}

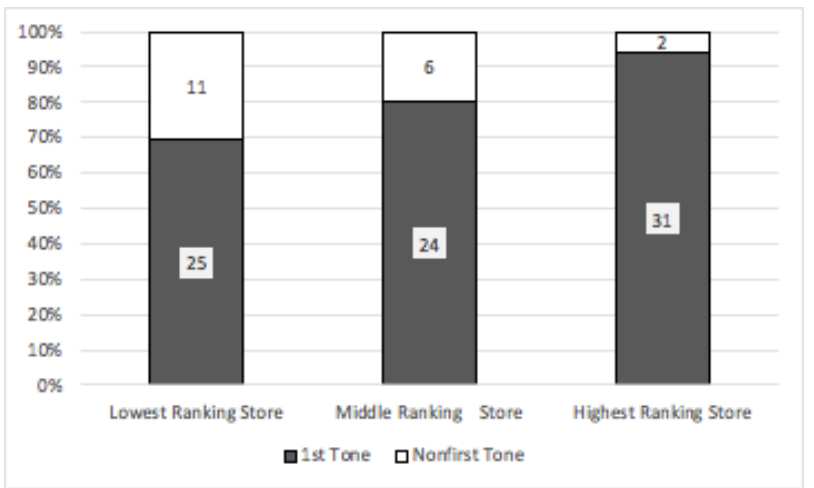

Figure 1. Overall tonal shift in pronunciation of "yi" by store (lowest ranking = Shuangxing Market, middle ranking $=$ New Mart, highest ranking $=$ Times Square and Parkland Mall)

Note. Shaded area $=\%$ first tone, unshaded area $=\%$ non-first tone

The results of the experiment clearly demonstrate a correlation between tonal shift and the ranking of the department store. Figure 1 visually shows that the tonal shift occurred in larger numbers in the lowest ranking stores and less so in the highest-ranking store. Figure 1 shows that tonal shift from first tone to non-first tone happened in $31 \%$ of the total pronunciations collected at the lowest ranking store, $20 \%$ at the middle ranking store, and $9.1 \%$ at the highest-ranking store.

Table 3. Number of non-first tone shifts by store

\begin{tabular}{cccc}
\hline Store & 1st Tone & Non-1st Tone shift & Total (sample size) \\
\hline Lowest Ranking & 25 & 11 & 36 \\
Middle Ranking & 24 & 6 & 30 \\
Highest Ranking & 31 & 2 & 33 \\
Total & 80 & 19 & 99
\end{tabular}

Chi square value: 6.6792

P-Value: 0.03545

Table 3 illustrates the same increasing trend of the number of non-first tone pronunciations from the highest-ranking stores to the lowest ranking store. The chi-square test was carried out for the data collected, and the chi-square value of 6.6792 was obtained. Based on this chi-square value, the corresponding p-value is 
0.03545 which is lower than the 0.05 standard, proving statistical significance of the data.

\subsection{The Effects of Other Independent Variables}

In this experiment, there are other variables present that might be the cause of the tonal shift pattern other than the socioeconomic class difference of targeted customers across the four department stores.

\subsubsection{Age Differentiation}

Table 4. Number of non-first tone pronunciations by estimated age groups

\begin{tabular}{ccccc}
\hline Estimated age group & Lowest Ranking Store & Middle Ranking Store & Highest ranking Store & Total \\
\hline $20-30$ & 1 & 3 & 1 & 5 \\
$35-40$ & 5 & 3 & 1 & 9 \\
45 and above & 5 & NA & NA & 5 \\
Total & 11 & 6 & 2 \\
& Chi square value: 6.6020 \\
\end{tabular}

Table 4 shows the number of non-first tone pronunciations by age group witin the three rankings of stores. There is no apparent trend in the numbers at hand (the P-value shows no significance of the data) which might partially be due to the lack of representation of the 45 and above age group in the middle and highest-ranking stores.

While collecting data, the interviewer noted down the informants' estimated age within five-year intervals. Though the data are merely impressionistic estimations, the data were divided into three age groups and analyzed in an attempt to detect any directional trends. Although it would be expected that the older age groups would have more tone shifts due to the increase in Standard Mandarin that the younger generations are taught to speak, the overall data shows no clear correlations in the age group pronunciations. It should be noted that the number of salespersons aged 45 and above decrease significantly as the ranking of the store increases. There were a number of informants within the third age group in the lowest ranking store (Shuangxing Market), but there was no informant above age 45 in the middle and highest-ranking stores (New Mart, Parkland, and Times Square). If a larger sample size with proper representation for all three age groups was interviewed at all four stores, then a more significant trend might be observed.

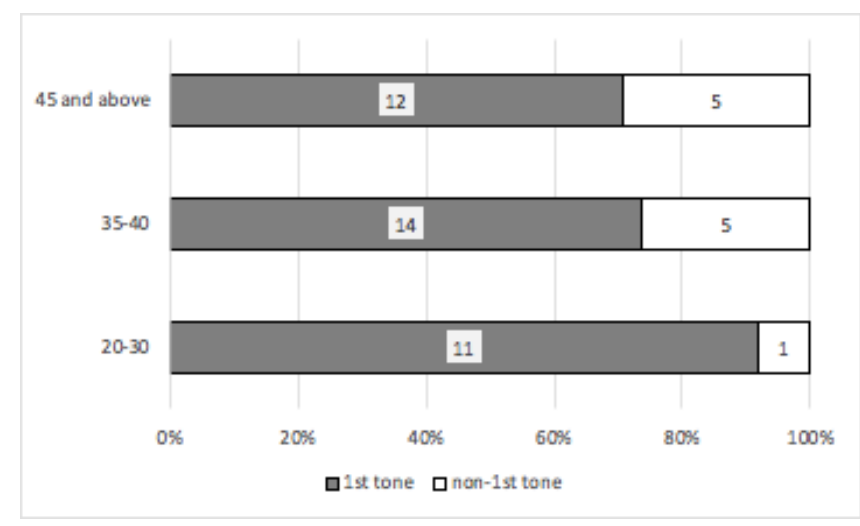

Figure 2. Percent first tone vs. non-first tone pronunciation by estimated age group in the lowest ranking store (Shuangxing Market)

Interestingly, if Shuangxing Market is examined individually (the only store with all age groups represented out of the four stores), the percentage of tonal shift in pronunciation does show an increase across age groups. As indicated in Figure 2 (below), the percentage of non-first tone pronunciation was 8.3\% in the 20-30 age group, $26.3 \%$ in the $35-40$ age group, and $29.4 \%$ in the 45 and above age group. As mentioned earlier in the introduction of this paper, the standardization of Mandarin has become more widespread in recent decades which could be a reason for the decreasing tonal shift pronunciation or dialect use in the younger age groups. According to recent surveys, the percentage of the population in China speaking Standard Mandarin increased significantly 
from 50\% in 2000 to $73 \%$ in 2017 (Wong, 2019). Most Chinese speakers naturally acquire a local dialect or adopt an accent through family speech and only become fluent in Standard Mandarin through formal school education. Therefore, the Compulsory Education Law enacted in 1986 and the higher education expansion launched in 1999 provide education to an increasing percentage of the population in China, leading to the higher numbers of Standard Mandarin speakers in recent generations. Nowadays in Dalian, it is far more common to hear Standard Mandarin in most social interactions than the local Dalian dialect. As a result, the younger generations' language acquisition process often lacks dialectical stimulus and memories.

\subsubsection{Impact of Regional Dialects}

In China, various regional dialects are spoken by people in different parts of the country, and Chinese migrant workers have been a major source in spreading these local dialects to other parts of the country. As a rapidly developing industrial city, Dalian has been and continues to attract migrant workers from across the nation. A majority of its workforce is made up of workers who are not local and speak dialects from other regions. Therefore, these regional dialects could be a factor impacting the variations recorded in this experiment. For instance, in Shuangxing Market, the interviewer heard multiple dialects being spoken in conversations between vendors, including Hunanese, Shanghainese, and Tianjinese. In particular, the second tone and fourth tone pronunciations of one word (yi) recorded in the data might have come from these other regional dialects spoken in the market. Specifically, Shanghainese pronounce the word with fourth tone (yì) and Jilu Mandarin (Tianjinnese) pronounce the word with second tone (yí). The second and fourth tone pronunciations were categorized under the non-first tone pronunciations in the result sections, but due to the limited data points (2) encountered in the data collection of this experiment, no correlation was evident. It could be of interest for future studies to categorize each tone of the pronunciation separately and investigate the tonal correlation with varying regional dialects in more depth.

\subsection{Possible Sources of Error}

Though Labov's 1962 study has been replicated multiple times and revised after each trial, there are still some sources of error inherent in the procedure and others that arose in this specific 2020 trial in Dalian, China. One of the major limitations in this 2020 experiment is the small sample population. In this study, there were a total of 99 informants interviewed, which is far fewer than the 269 subjects Labov interviewed. As a result, the smaller sample population may lead to narrow applications for the research results. In addition, the sample in this experiment was focused on female subjects which prevents any conclusion from being made about linguistic variations within the male population. While the number of subjects interviewed at stores of the three different rankings are relatively even, due to the smaller sample size, not all age groups were equally represented in each department store. Therefore, no definitive trend was observed when trying to analyze correlations between age groups and tonal shift in pronunciation across the stores.

Secondly, in carrying out this experiment, the researcher is making the assumption that the interviewed salespersons are perceiving the interviewer (the researcher), as the targeted customer class of their given store. The way that the interviewer was dressed and the way that the interviewer spoke might have impacted the salespersons' perception about the interviewer's socioeconomic class. Due to this, their response might have been influenced and may not reflect accurately what their language usage would have been in an interaction with a customer of the store's targeted class.

Another source of error that Labov also indicated in his original 1962 research is that the pronunciation data (audio) were not recorded. The interviewer took note of each tonal pronunciation, but the human ear is only so accurate, and the interviewer's awareness of the desired answer might lead to biased data collection. The interviewer attempted to eliminate this source of error by recording the "interviews" on her phone which was placed discreetly in her pocket to prevent the informant from seeing. However, this attempt failed as the recordings were muffled and could not be made clearer by tonal detection software.

If the experiment were to be carried out again, there are some potential remedies to lessen the effect of these sources of error. First, the size of the sample population could be increased if multiple stores were selected for each class ranking (lowest, middle, highest), and more pronunciation data would be collected this way to increase representativeness of the observed patterns. With a larger sample population, the interviewer could also try to include informants from all age groups from all the stores visited. In this way, there would be a greater degree of confidence in the results. The interviewer might also ask for biographical information after eliciting the pronunciation data so the age data could be accurately recorded instead of using impressionistic assumptions.

Lastly, if the interviewer could carry a discreet recording device to allow him/her to properly record pronunciations without suspicion then the data could be analyzed more carefully and accurately with tonal 
detection software. In this manner, the interviewer could also plan to have longer conversations in the interview which would allow for the collection of more data points for later analysis.

\section{Discussion}

The hypothesis set forth in the beginning of this paper was confirmed through the experimental data that demonstrate a direct relationship between socioeconomic class and the dialectical tonal shift pronunciations. This conclusion was tested within the department store setting and proves tonal shift to be an integral part of the local dialect.

One possible explanation for this correlation might be found in the accommodation theory, which indicates that speakers accommodate or adjust their speech to that of their interlocutors in order to seek approval or to reduce social distance (Giles et al., 1987, p. 4). Specifically, the salespersons in each store may be adjusting their speech to accommodate the targeted socioeconomic class of customers, resulting in either tonal shifts or maintaining the Standard Mandarin pronunciation. For instance, although a Times Square salesperson's native dialect puts a tonal shift on the pronunciation of "yi," he/she might intentionally choose to pronounce the word with first tone following Standard Mandarin in order to better suit the higher-class customers that the store targets. In this manner, a salesperson's instinctive responses under the setting of each department store would differ based on the socioeconomic class of their customers.

Generally, this intentional choice of changing one's language usage can be called "code-switching." All the local dialects as well as Standard Mandarin are codes of communication in China. More specific to this experiment, the switch to first tone pronunciations from all non-first tone pronunciations are expressions of code-switching from dialect to Standard Mandarin, which took place more frequently in the highest-ranking stores. This code-switching demonstrates the prestige that the salesperson associates with his/her customers. Similar results were identified in a 2018 experiment carried out in Malaysia titled "Prestige of products and code-switching in retail encounters." In this study, researchers found that English used within retail encounters marked prestige of products, especially in cars and credit cards, whereas beauty and food products were promoted mostly in the local dialects of Hokkien or Malay (Ting et al, 2018).

Education is another important factor to consider in attempting to justify the differences in language use within different social class settings. Education institutions in China require teachers to use Standard Mandarin in their instruction, and students acquire familiarity with Standard Mandarin in this way. Due to the social stratification of education access in China, those born into the middle lower class or working class have less access to general education and higher education. Parents with higher socioeconomic status utilize their economic resources and social networks to help their children get into key-point schools (whose graduates are more likely to be admitted into higher education than non key-point school graduates) (Wu, 2017). In addition, these parents also have the awareness and financial resources to guide their children to participate in extracurricular activities so as to meet the criteria for independent admission (Bourdieu and Passeron, 1977; Karabel, 2005). Conversely, parents from lower socioeconomic classes have less experience in these areas (as they themselves might not have even had any access to education) and are likely to be pushed into an even more disadvantaged position (Wu, 2017, p.11). Specifically, rural-urban disparity plays a central role in current Chinese social inequalities (Hong \& Qian, 2010, p.6). In rural parts of China, lack of education resources and awareness remain a major issue that is preventing upward social mobility. As a result, children in rural areas have fewer opportunities to learn Standard Mandarin, and many of them who later become migrant workers still rely on their local dialect in communication regardless of location.

While this 2020 study focused on the variation in pronunciation that occurred in Dalian department stores, the tonal shift occurs as a result of social stratification not only in Dalian dialect. Though a relatively small number of studies have explored the social implications of language variation within Chinese dialects, there is evidence in various regional dialects demonstrating the impact of social factors on language change. One study titled "A Brief Introduction on a Research of Lanzhou Tonal Variation" investigated the merging of two tonal variants ("Shangsheng" and "Qusheng") and examined the tonal variation in terms of different social factors, including age, gender, and education. The results suggested that speakers with higher education and stable employment pronounced "yinping" with a level contour (Yi \& Wen, 2017). This finding serves as an indication that the social implications of language usage proved in this 2020 Dalian experiment are not only applicable in the study's narrow location of Dalian city but also present in other regional dialects of the nation at large.

This 2020 study limited the sample population to only female informants, excluding the gender confounding factor. Further studies could compare the expression of the same linguistic trend studied in this paper between genders. This direction of study could yield interesting data about any differences in usage of language 
determined by gender and help to gain insights into varying social behaviors of gender seen through the linguistic lens. To build on this study, future studies could also examine the tonal shift across various Chinese dialects and generate findings about regional language variances, in terms of their correlation with socioeconomic class, based on the similarities and differences found through empirical study.

In this paper, the direct correlation between tonal shift and dialect usage with socioeconomic class was established through an experiment adapted from Professor William Labov's original 1962 study in New York. In the four department stores surveyed, the highest occurences of non-first tone pronunciations were recorded in the store catering to a lower socioeconomic class, while the lowest occurances were in the stores targeting higher socioeconomic class customers. This study sheds light on the similar social implications of dialect usage in Dalian, China to those studied by Professor Labov in New York City. Finally, the limitations and potential evident in this 2020 study offer topics for further exploration to expand the findings to wider applications.

\section{Acknowledgments}

I would like to thank Professor Lindsay Whaley and Jessica McDermott from Dartmouth University for all their guidance and support on this paper.

\section{References}

Bourdieu, P., \& Passeron, J. C. (2014). Reproduction in education, society, and culture (R. Nice, Trans.; 2nd ed.). Sage.

Bright, W. (1960). Social Dialect And Language History. Current Anthropology, 1(5/6), 424-425. https://doi.org/10.1086/200137

China salvages local dialects as Mandarin prevails. (2012, September 6). ChinaDaily. https://www.chinadaily.com.cn/china/2012-09/06/content_15739254.htm

Egerod, S. C. (2013, October 7). Chinese languages. Encyclopaedia Britannica Online. https://www.britannica.com/topic/Chinese-languages

Giles, H., Mulac, A., Bradac, J., \& Johnson, P. (1987). Speech Accommodation Theory: The First Decade and Beyond. Communication Yearbook, 10(1), 4. https://doi.org/10.1080/23808985.1987.11678638

Gilliland, J. (2006). Language Attitudes and Ideologies in Shanghai, China. (Electronic Thesis or Dissertation). Retrieved from https://etd.ohiolink.edu/

Guy, G. (1988). Language and social class. In F. Newmeyer (Ed.), Linguistics: The Cambridge Survey (pp. 37-63). Cambridge: Cambridge University Press. https://doi.org/10.1017/CBO9780511620577.004

Hong, Y., \& Qian, M. (2010). Educational and Social Stratification in China: Ethnicity, Class, and Gender. Chinese Education \& Society, 43. 3-9. https://doi.org/10.2753/CED1061-1932430500

Karabel, J. (2014). The chosen: The hidden history of admission and exclusion at Harvard, Yale, and Princeton. A Mariner Book Houghton Mifflin Company.

Labov, W. (2006). The social stratification of English in New York City (2nd ed.). Cambridge University Press. https://doi.org/10.1017/CBO9780511618208

Mather, P.-A. (2012). The Social Stratification of $/ \mathrm{r} /$ in New York City: Labov's Department Store Study Revisited. Journal of English Linguistics, 40(4), 338-356. https://doi.org/10.1177/0075424211431265

Matthews, P. (2014). 'observer's paradox'. In The Concise Oxford Dictionary of Linguistics. Oxford University Press. Retrieved August 21, 2020, from https://www.oxfordreference.com/view/10.1093/acref/9780199675128.001.0001/acref-9780199675128-e-2 311.

Shuy, R. W., Wolfram, W., \& Riley, W. K. (1967). Linguistic correlates of social stratification in Detroit speech. East Lansing: Michigan State University.

Ting, Su-Hie \& Chen, David \& Ong, Oliver. (2018). Prestige of products and code-switching in retail encounters. International Journal of Multilingualism, 17. 1-17. https://doi.org/10.1080/14790718.2018.1559321

Weng, J. (2018). What Is Mandarin? The Social Project of Language Standardization in Early Republican China. The Journal of Asian Studies, 77(3), 611-633. https://doi.org/10.1017/S0021911818000487

Wong, W. (2019, February 21). The Slow Death of China's Dialects. The McGill International Review. https://www.mironline.ca/the-slow-death-of-chinas-dialects/ 
World Heritage Encyclopedia. (n. d.). Dalian dialect. Project Gutenberg Self Publishing Press. Retrieved from http://self.gutenberg.org/articles/eng/Dalian_dialect

$\mathrm{Wu}, \mathrm{X}$. (2017). Higher education, elite formation and social stratification in contemporary China: Preliminary findings from the Beijing College Students Panel Survey. Chinese Journal of Sociology, 3(I)(3-31), 11-12. http://doi.org/10.1177/2057150X16688144

Yi, L., \& Wen, T. (2018). A Brief Introduction on a Research of Lanzhou Tonal Variation. Studies in Linguistics and Literature, 2, 244. https://doi.org/10.22158/sll.v2n4p244

Dalian New Mart Department Store. (n. d.). Mafengwo. Retrieved from http://www.mafengwo.cn/poi/27573.html

Dalian Times Square. (n. d.). BaiduBaike. Retrieved from https://baike.baidu.com/item/\%E5\%A4\%A7\%E8\%BF\%9E\%E6\%97\%B6\%E4\%BB\%A3\%E5\%B9\%BF\%E $5 \% 9 \mathrm{C} \% \mathrm{BA}$

\section{Copyrights}

Copyright for this article is retained by the author(s), with first publication rights granted to the journal.

This is an open-access article distributed under the terms and conditions of the Creative Commons Attribution license (http://creativecommons.org/licenses/by/4.0/). 